\title{
Social functioning in schizophrenia: what is the influence of gender?
}

\author{
Judith Usall, Ph.D.* \\ Josep M Haro, Ph.D.* \\ Susana Araya, M.D.* \\ Berta Moreno, Ph. D.** \\ Pedro Enrique Muñoz, Ph.D.*** \\ Alfredo Martínez, M.D.**** \\ Luís Salvador, Ph.D. ${ }^{\star \star \star \star \star}$ \\ and PSICOST group
}

* Sant Joan de Déu, Serveis Salut Mental. Barcelona

** Faculty of Psychology University of Granada

*** Hospital Virgen del Camino Irunlarrea Pamplona

**** Mental Health Comunidad de Madrid Epidemiology Area

***** University of Cadiz

SPAIN

ABSTRACT - Background and Objectives: To examine the influence of gender on social functioning in patients with schizophrenia

Methods: A sample of 318 schizophrenic (216 men and 102 women) (DSM-IV criteria) outpatients from four Spanish centres were administered the following instruments: Positive and Negative Symptom Scale (PANSS), Disability Assessment Scale (DAS-sv), and Global Assessment of Functioning (GAF) Scale. A regression model was created with DAS and GAF as dependent variables, and gender, and other predictor variables as independent variables. Separate regression models were then generated for females and males.

Results: Women had a better social functioning than men, and after adjusting for others predictor variables gender was a significant predictor specially for occupational functioning. In gender specific analyses, we found that the predictive variables for social functioning have more similarities than differences between men and women.

Conclusions: In our sample, women showed a better social functioning than men specially in occupational functioning. 


\section{Introduction}

Gender differences in patients with schizophrenia have frequently been reported with respect to age at onset, premorbid functioning, course of illness, familial transmission and neurobiological factors ${ }^{1-3}$. Most studies have found that women have a better functioning than men ${ }^{4}$. However, previous research has usually employed sociodemographic variables to measure social functioning ${ }^{5-7}$, which has relevant limitations compared to using specific assessment scales. Moreover, most previous studies do not adjust for the presence of cofounding factors that could affect the differences between men and women, such as age at onset or severity of symptoms. We have previously reported that the gender influence on social functioning seems to be independent from symptomatology, age of onset, length of illness and marital status, but only in some areas of functioning, especially occupational one ${ }^{8}$.

Social outcome measures are useful to evaluate prognosis in schizophrenia because they include not only illness and treatment factors but also those related to occupational gender roles 9 .

The aim of the study is to examine the influence of gender in social functioning after adjusting for possible confounding variables (such as age at onset, duration of illness, marital status, symptomatology, menopausal status and others) in a large sample of outpatients with schizophrenia.

\section{Material and methods}

\section{Subjects}

This study is part of a coordinated project intended to assess clinical status, psychoso- cial disability, health-related quality of life, family burden, heath service utilization and direct and indirect costs of people with schizophrenia in Spain.

The four mental health clinics that participated in the study were located in Gavà (Barcelona), Loja (Granada), Salamanca district (Madrid), and Burlada (Pamplona). In each of the centres, a representative treated prevalence sample of cases with schizophrenia was selected. Inclusion criteria were: diagnosis of schizophrenia (DSM-IV criteria), age between 18 and 65 years and to have been contact with the mental health care centres of the catchment areas during the six-month inclusion period. Patients with a primary diagnosis of neurological disorder or mental retardation were excluded. Sample size calculation determined that at least 80 subjects should be included in each centre. In Granada, Madrid and Navarra, all cases that fulfilled entry criteria were included. In Barcelona, due to the size of the area, a random sample of cases was selected. All patients gave oral informed consent to participate in the study.

\section{Evaluation}

The evaluation was conducted by interviewing patients and family members, when available. The assessment included the Spanish version of the Positive and Negative Syndrome Scale (PANSS) ${ }^{10,11}$; the DSM-IV Global Assessment of Functioning (GAF) scale ${ }^{12}$; and the WHO's Disability Assessment Scale (DAS)- short version ${ }^{13}$ which evaluates four areas of disability, namely personal care, family roles, work and social adaptation from 0 (no disability) to 5 (maximum disability). The PANSS symptoms were grouped in accordance with Kay's five factors model ${ }^{14}$. The interviews were conducted by clinicians that were 
trained in the administration of the instruments. Age at onset was defined as age of first psychotic symptoms. Late onset was defined as onset after 45 years of age. Although menopausal status was not endocrinologically confirmed, we have considered 50 the modal age for women transitioning into menopause.

\section{Data analysis}

Besides descriptive statistics, linear regression analysis with stepwise model reduction was used to evaluate the influence of gender on social functioning after adjusting for the presence of other predictor variables. The GAF scale and the DAS total score and subscales were used as dependent variables and gender, PANSS, marital status, age at onset, duration of illness and age as independent variables. Age at onset was categorized into three levels (less than 18 years, from 18 to 44 and more than 44 years) and duration of illness into two (less than and more than 10 years of duration).

To analyse the consistency of the findings, we performed an independent linear regression analysis for each gender. The final models include only the variables that were significant at 0.05 significance level.

\section{Results}

Three hundred and fifty-six patients (244 men and 112 women) were selected, and 318 were finally included in the study (216 men and 102 women), with a refusal rate of $10 \%$. The women were older than the men; the mean age of the women was 40.59 years ( sd 9.74) versus 37.45 ( sd 9.74) in men ( $p$ < 0.01 ). The women also had a higher age of onset (mean of 25.3 [sd 8.1] for women versus 23.4 years [sd 6.8] for men, $\mathrm{p}<0.05$ ), and were more often married $(23 \%$ of women compared to $9.4 \%$ of men, $\mathrm{p}<0.01$ ). No statistically significant gender differences were found in duration of illness or PANSS dimension scores.

Table I shows social functioning and disability by gender. Mean GAF scores were significantly higher in women. Men were more disabled as assessed by the DAS scale in occupational functioning and total disability.

Table II shows the multiple regression analysis with GAF and DAS as dependent variables. Gender was a significant predictor for GAF, total DAS, and occupational functioning DAS. In all cases, women had a better functioning. Positive, negative and excited symptoms predicted lower functioning and higher disability in almost all mod-

Table I

Social functioning and disability by gender.

\begin{tabular}{lcc} 
& $\begin{array}{c}\text { Men } \\
\mathrm{N}=244 \\
\text { Mean }(\mathrm{sd})\end{array}$ & $\begin{array}{c}\text { Women } \\
\mathrm{N}=112 \\
\text { Mean (sd) }\end{array}$ \\
\hline Global Assessment of Functioning (GAF) & $46.6(15.8)$ & $52.3(17.3)^{*}$ \\
WHO-Disability Assessment of Functioning (DAS) & & \\
Personal care & $1.8(0.9)$ & $1.9(1)$ \\
Occupational & $4.3(1.2)$ & $3.6(1.5)^{* *}$ \\
Family & $2.3(1.1)$ & $2.3(1.2)$ \\
Social & $2.7(1.1)$ & $2.6(1.2)$ \\
Total & $2.5(0.9)$ & $2.1(1)^{*}$ \\
\hline
\end{tabular}

$* \mathrm{p}<0.05$

$* * \mathrm{p}<0.01$ 


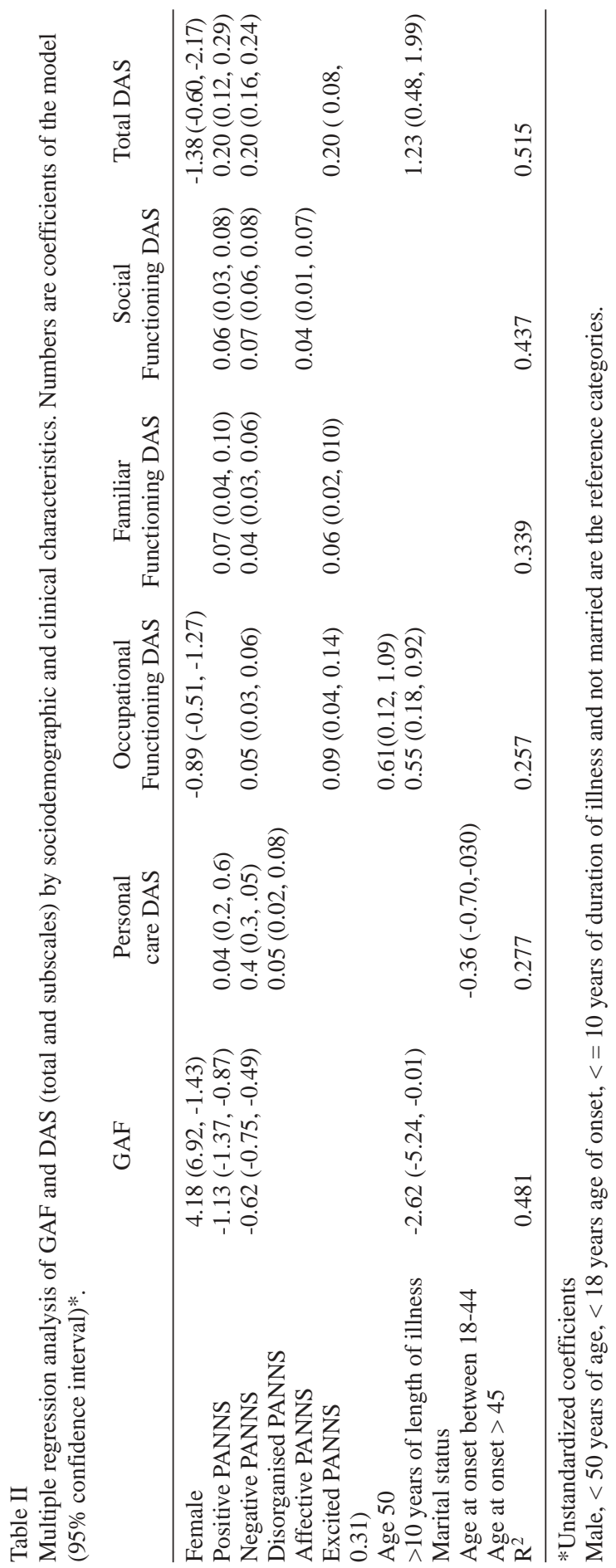


els. A shorter duration of illness predicted a better functioning. To be more or equal than 50 years old predicted a higher score only in occupational functioning. The R2 scorings were higher especially in the total DAS and GAF regression models.

The main results of the separate regression models for females and males were as follows: a) the GAF score was significantly associated with positive and negative PANSS and duration of illness in both sexes; b) marital status predicted a better functioning as measured with the GAF only in men; c) DAS-total score was significantly associated with negative PANSS and duration of illness in both sexes; d) positive PANSS influenced total DAS only in men; and e) excited PANSS predicted total DAS in women. These models (especially those for females) accounted for a high proportion of the variance of the data ( $40 \%$ or more).

\section{Discussion}

One of the findings of our study is that when we have compared social functioning between women and men with schizophrenia, without and after adjusting for other predictor variables, we have found that social functioning was better in women than in men. This result replicates previous findings of a better social adjustment in schizophrenic women ${ }^{6,9,15-17}$. We employed specific scales to evaluate social functioning (the DAS and the GAF scales) because, as other authors have reported, the use of sociodemografic indicators (such as marital status) to measure outcome in schizophrenia is problematic ${ }^{18,19}$.

After adjusting for others predictor variables, however, we found that gender had not an equal influence on the different areas of social functioning. Specifically, gender differences were only important in the occupational subscale of the DAS. Other studies employing the DAS to assess gender differences in social functioning of schizophrenic patients ${ }^{8,20}$ found better outcomes in women in other areas in addition of the occupational ones. Our present finding could be interpreted in the light of the differences in gender occupational roles which still exist in our society; for instance, there was a majority of housewives in our female sample.

Interestingly, variables such as symptomatology and duration of illness and age at onset $^{8,21}$, had also influence in social functioning.

In order to examine the influence of menopausal status on social functioning, we included two variables among the predictor variables: late age at onset, defined as more than 45 years; and age over 50 years. Our finding was that being over age 50 and later age at onset did not have an important influence on social functioning.

Overall, our results from the separate regression models revealed no relevant differences among the predictive variables for social functioning between females and males. We found that duration of illness has the same influence in both sexes. This is in contrast with our results from a previous study $^{8}$, where this variable did predict worse social functioning only in men.

Several limitations of our study should be noted. First, the sample is not evenly balanced with respect to gender distribution, although the excess of male patients in our sample is consistent with the gender composition of schizophrenic subjects reported by most studies ${ }^{22,23}$. Second, our sample was selected from people with schizophrenia who were receiving treatment in public out- 
patient clinics, and this may not be representative of the total population of people with schizophrenia. Third, there is a definitional problem with respect to classification of menopausal status because this was not endocrinologically confirmed. Fourth, we have not controlled by treatment compliance, not by recent psychotic episode. Among the strengths of our study, which make our results more generalizable, we should highlight the large sample and the multicentric approach.

In conclusion, we have found that: a) the most important gender difference in social functioning was related to occupational functioning; b) menopausal status did not influence social functioning; and c) the predictive variables for social functioning are more similar than different for men and women.

\section{Acknowledgements}

Supported by the Spanish Ministry of Health, Instituto de Salud Carlos III, RETICS RD06/0011 (REM-TAP Network), Grant FIS 97/1298 - FIS 97/1275, Thematic network RIRAG G03/061, and RedIAPP network RD06/0018/0039.

\section{References}

1. Haro JM, Eaton WW, Bilker W, Mortensen PB. Predictability of rehospitalisation for schizophrenia. Eur Arch Psychiatry Clin Neurosc 1994; 244; 241-246.

2. Leung A, Chue P Sex differences in schizophrenia, a review of the literature. Acta Psychiatr Scand 2000; 101: 3-38.

3. Usall J, Busquets E, Araya S, Ochoa S, Gost A Diferencias de género en la esquizofrenia. Una revisión de la literatura. Actas Esp Psiquiatr 2000; 3: 178- 185.
4. Angermeyer MC, Kühn L, Goldstein JM Gender and the course of schizophrenia: differences in treated outcomes. Schizophr Bull 1990; 16(2): 293-307.

5. Test MA, Burke SS, Wallisch LS. Gender differences of young adults with schizophrenic disorders in community care. Schizophr Bull 1990; 16(2): 331-344.

6. McGlashan Th, Bardenstein KK. Gender differences in affective, schizoaffective, and schizophrenic disorders. Schizophr Bull 1990; 16(2): 319-329.

7. Salokangas RKR, Stengard E. Gender and short-term outcome in schizophrenia. Schizophr Res 1990; 3: 333-345.

8. Usall J, Haro JM, Ochoa S, Márquez M, Araya S, and NEDES Group (Assessment Research Group in schizophrenia). Influence of gender on social outcome in schizophrenia. Acta Psychiatr Scand 2002; 106: 337-342.

9. Haas GL, Glick ID, Clarkin JF, Spencer JH, Lewis AB. Gender and schizophrenia outcome: a clinical trial of an inpatient family intervention. Schizophr Bull 1990; 16(2): 277-292.

10. Kay SR, Fizben A, Opler LA. The positive and negative syndrome scale (PANSS) for schizophrenia. Schizophr Bull 1987; 13: 261-276.

11. Peralta V, Cuesta MJ. Validación de la escala de los síndromes positivo y negativo (PANSS) en una muestra de esquizofrénicos españoles. Actas Luso-Esp Neurol Psiquiatr 1994; 22,4: 171-177.

12. American Psichiatric Association. Diagnostic and statistical manual of mental disorders. 3rd ed. revised. 1987 Washington, DC.

13. World Health Organization. WHO Psychiatric Disability Assesment Schedule. 1988. Geneva: World Health Organization.

14. Kay SR, Sevy S. Pyramidical model of schizophrenia. Schizophr Bull 1990; 16: 537-544.

15. Andia AM, Zisook S, Heaton RK et al. Gender differences in schizophrenia. J Nerv Ment Dis 1995; 183(8): 522-528.

16. Vázquez-Barquero JL, Cuesta MJ, Herrera S, Lastra I, Herrán A, Dunn G. Cantabria first-episode schizophrenia study: three-year follow-up. Brit J Psychiatry 1999; 174: 141-149.

17. Ochoa S, Usall J, Villalta-Gil V, Vilaplana M, Márquez $\mathrm{M}$, Valdelomar $\mathrm{M}$ et al. Influence of age at onset on social functioning in outpatients with schizophrenia. Eur. J Psychiat 2006; 20(3): 157-163.

18. Walkup J, Gallaher SK. Schizophrenia and the life course: national findings on gender differences in disabi- 
lity and service use. Int. J. Aging and human development 1999; 49(2): 79-105.

19. Nasser E, Walders N, Jenkins JH. The experience of schizophrenia: what's gender got to do with it? A critical review of the current status of research in schizophrenia. Schizophr Bull 2002; 28(2): 351-362.

20. Chaves AC, Seeman MV, Mari JJ, Maluf A Schizophrenia: impact of positive symptoms on gender social role. Schizophr Res 1993; 11(1): 41-45.

21. Häfner H, An Der Heiden W, Behrens S et al. Causes and consequences of the gender difference in age at onset of schizophrenia. Schizophr Bull 1998; 24(1): 99113.
22. Iacono WG, Beiser M. Are males more likely than females to develop schizophrenia? Am J Psichiatry 1992; 149: 1070-1074

23. Kendler KS, Walsh D. Gender and schizophrenia. Results of an Epidemiologically-based Familiy Study. Br J Psychiatry 1995; 167: 184-192.

Address for correspondence: Dr Judith Usall Research and Development Unit Sant Joan de Déu - Serveis de Salut Mental C/ Dr. Antoni Pujadas 42 08830 St. Boi de Llobregat. SPAIN e-mail: jusall@sjd-ssm.com Tel \#: 00-34-93-6406350 